\title{
Consumer Policy in the Age of Covid-19
}

\section{A. Mathios ${ }^{1} \cdot$ H.-W. Micklitz ${ }^{2} \cdot$ L. A. Reisch ${ }^{3} \cdot$ J. Thøgersen ${ }^{4} \cdot$ C. Twigg-Flesner ${ }^{5}$}

Published online: 29 May 2020

(C) Springer Science+Business Media, LLC, part of Springer Nature 2020

We started 2020 with a special issue celebrating 40 years of consumer law and policy scholarship in the Journal of Consumer Policy. Many of the papers in the first issue of the current volume looked ahead to the challenges consumer law and policy would face in the future, especially as a result of digitalization and internationalization. Since then, to use a cliché, the world has changed dramatically and in a way few of us could have imagined. Towards the end of 2019, the world became aware of a new type of coronavirus, now known as Sars-Cov-2, which can cause a disease now known as Covid-19, which can be serious and sometimes fatal. Having first been reported in China, it rapidly spread around the world and became a pandemic. Millions around the world have been infected, hundreds of thousands have been hospitalized with severe forms of Covid-19, and several hundred thousand people have died after being infected with Sars-Cov-2. In many countries around the globe, people have had to go into lockdown - stay at home, work from home, and only leave for essential trips. Everyone has had to adapt to social distancing - keeping apart from non-household members by two metres. Many businesses have had to suspend their activities, with staff either

C. Twigg-Flesner

C.Twigg-Flesner@warwick.ac.uk

A. Mathios

adm5@cornell.edu

H.-W. Micklitz

hans.micklitz@eui.eu

L. A. Reisch

lre.msc@cbs.dk

J. Thøgersen

jbt@mgmt.au.dk

1 Cornell University, Ithaca, NY, USA

2 European University Institute, Florence, Italy

3 Copenhagen Business School, Frederiksberg, Denmark

4 The Aarhus School of Business, Aarhus, Denmark

5 School of Law, University of Warwick, Coventry, UK 
laid off or furloughed. The economic impact of the pandemic will be severe, and the 2008 financial crisis will likely pale in comparison.

These are worrying times for everyone around the globe. Invariably, these developments have not left consumers unscathed. Many consumers have lost their income and have to manage with much reduced resources. At the same time, prices of some essential goods have risen sharply as supplies have come under pressure from high levels of demand and in some cases fuelled by panic-buying. Some unscrupulous people who managed to acquire essentials have offered them for sale via online auction sites at inflated prices. Furthermore, many consumers had already paid for travel, holidays, and events which have since had to be cancelled because of the pandemic but have had to deal with businesses unwilling to issue refunds in the face of their own financial circumstances. Vouchers have been offered instead; some businesses have refused to provide anything. Quack medicines have emerged, falsely offering prevention or cure of Covid-19. Consumers who have loans to service and rents to pay face the risk of defaults, eviction, and maybe insolvency, and many governments have intervened to offer some respite through moratoria and protection from eviction.

Government responses to the pandemic also highlight the tension between consumer privacy and public health. Monitoring social distancing behaviour might be an important tool for governments as they seek to curb the community spread of the disease. The use of technology to monitor where consumers have been and to whom they have been in close proximity can enable public health officials to track contacts, should someone test positive for the virus. What are, and what should be, the limits of this type of government surveillance in a free society? Which governance rules do we need to balance the obvious benefits of such tracking applications with the severe privacy infringements they will necessarily entail? These are fundamental consumer policy issues. The balance struck by different governments will likely vary based on each country's culture and history.

One of the consequences of lockdowns, travel restrictions, and financial impacts is that many consumers will be adjusting their consumption behaviours - partly as a matter of conscious reflection and partly because the circumstances compel such a change. As air travel has all but collapsed, and digital communication tools have become the substitute for travel and get-togethers, a "new normal" may emerge in which rapid consumption is moderated and sustainability concerns may gain greater prominence. Moreover, awareness of strategies to limit the community spread of viruses may have longer lasting positive impacts. Year after year, hundreds of thousands of people die from complications of the typical flu. Will consumer behaviour around hand washing, shaking hands, touching the face, and other prevention strategies last into future years somewhat limiting the spread of the common cold and more common flu? Will consumers be more inclined to vaccinate against the flu in the future? Future deaths might be reduced should some of the emergency precautions consumers now take become part of the culture. Handshaking is an interesting example. Originally designed to reveal that someone is not a threat (and not holding a weapon), this tradition has lasted for centuries. Will the current pandemic be the end to a long-standing western tradition that immediately produces connectedness? What about the social consequences if we hide our faces behind masks and our counterpart might have difficulties to identify the person behind and read in our face? These are very interesting consumer behavioural questions with potentially impactful public health consequences.

Of course, at this time, we do not know what will happen. However, it is highly unlikely that we will do what Bruce Springsteen did when he was cut off mid-song in London a few years ago due to the curfew time and started his next gig at exactly that mid-song point. Things 
will be different when we emerge from this crisis, when lockdowns are lifted, and social distancing will no longer be mandatory. All of this will have significant implications for consumer law and policy and will result in exciting and novel consumer policy research.

Since its rise in the 1960s, consumer policy has been open to the criticism that it advances the interests of middle-class consumers to the detriment of poor consumers. What does consumer policy look like in a state of emergency? Will the experiences after the Lehman collapse and the Euro crisis, in the wake of which public policy measures meant to support consumers privileged the rich over the poor, be repeated? What is the role of consumer organizations at the time of crisis? What kind of role should civil society organizations play in a world dominated by consumption? All these and other questions will tell us how reliable consumer policy in difficult times is and to what extent it changes its focus and substance.

As editors of the Journal of Consumer Policy, we discussed how the JCP should respond to the crisis. Several other academic journals opted for a rapid response strategy, for example, and we considered whether to give the current issue a special "Corona" focus. A small number of submissions started to come in as we prepared this issue. In the end, we felt that, rather than inviting a running commentary on a crisis which will have a long time to run yet (even if there is a sudden medical breakthrough), we should encourage consumer policy and consumer law scholars to take a longer-range perspective. In the near future, there will be an urgent need to study what we can learn from the experiences of consumers during this crisis and what this means for consumer policy in its behavioural science, economics, and law dimensions. We are keen to publish original and rigorous papers in this vein and invite consumer policy scholars from all disciplines to submit their work to us. We intend to issue a call for papers for a special issue in a year's time, when the urgency of the crisis will hopefully have gone, and we can see the road ahead clearly again. In the meantime, we will, of course, evaluate any submissions on Covid-19 and consumer policy on their merits.

For now, we hope that all our readers and their families keep safe and well.

Publisher's Note Springer Nature remains neutral with regard to jurisdictional claims in published maps and institutional affiliations. 